\section{Tamponade in Dressler's Syndrome with Immunological Studies}

\section{S. T. A. LAWRENCE, RALPH WRIGHT}

British Medical fournal, 1972, 1, 665-666

In his paper defining the postinfarction syndrome, Dressler (1959) noted that "although pericarditis may lead to tamponade in the absence of anticoagulants this was not seen in this series." We here record such a case and also show that the syndrome occurred in a patient liable to hypersensitivity reactions.

\section{Case Report}

A 67-year-old widow developed asthma in 1956 and had had eczema since her youth. Skin testing showed her to be sensitive to pollen; pets and many plants made her wheeze, and she was sensitive to penicillin. For the past five years she had experienced a tight substernal pain on exertion and had had one episode of paroxysmal atrial tachycardia but without evidence of a myocardial infarct. Two weeks before admission she had had severe chest pain of sudden onset, which recurred on the day before admission. On physical examination she was found to be short of breath at rest and coughed up frothy sputum but no gallop rhythm or basal crepitations were present. The thyroid was not palpable, temperature was $37.5^{\circ} \mathrm{C}$, blood pressure was $120 / 80 \mathrm{~mm} \mathbf{H g}$. LDH $40 \mathrm{mU} / \mathrm{ml}$; SGOT $30 \mathrm{mU} / \mathrm{ml}$; E.C.G. T-wave inversion in lead aVF.

Five days after admission she complained of pain in the epigastrium. The SGOT $(160 \mathrm{mU} / \mathrm{ml})$ and $\mathrm{LDH}(245 \mathrm{mU} / \mathrm{ml})$ became raised and $Q$ waves and $S-T$ elevation appeared in leads III and aVF consistent with myocardial infarction. The pain occurred intermittently although the SGOT fell to normal. Ten days later a pericardial friction rub was heard at the apex. The following day

Nuffield Department of Clinical Medicine, Radclifie Infirmary,
Oxford

M. S. T. A. LAWRENCE, M.B., B.CH., House Physician Medicine, University of Southampton)
MLPH WRIGician (Now Professor of this was inaudible but chest $x$-ray examination showed a large pericardial effusion (see Fig.) and she became increasingly short of breath. Jugular venous pressure raised $4 \mathrm{~cm}$; blood pressure 110/ $70 \mathrm{~mm} \mathrm{Hg}$, with $10 \mathrm{~mm}$ paradoxical pulse; temperature $37^{\circ} \mathrm{C}$; SGOT $97 \mathrm{mU} / \mathrm{ml}$; LDH normal; E.S.R. $83 \mathrm{~mm} / \mathrm{hr}$.

A total of $400 \mathrm{ml}$ of straw-coloured fluid was aspirated from the pericardium with striking symptomatic improvement. Eleven days later she developed pleuritic pain and a small pleural effusion with haemoptysis. Prednisolone $40 \mathrm{mg}$ daily was started and within a week the E.S.R. fell to $6 \mathrm{~mm} / \mathrm{hr}$. There was an exacerbation of pain together with a rise in E.S.R. when the dose of prednisolone was first reduced. Nine months after the acute episode she was well but remained prone to episodes of paroxysmal atrial tachycardia. Rose-Waaler test, tests for L.E. cells and A.N.F., W.R., and Kahn test negative; immunoglobulins normal; A.S.O. titre $200 \mathrm{U} / \mathrm{ml}$; P.B.I. $5.8 \mu \mathrm{g} / 100 \mathrm{ml}$; T-3 resin uptake $29.4 \%$; pericardial fluid: no malignant cells, red cells, or growth.

Immunological Tests.-Specimens of serum and pericardial fluid were tested for a variety of autoantibodies by indirect immunofluorescence. Autoantibodies to heart with a sarcolemmal-subsarcolemmal pattern of staining, a pattern often observed in this syndrome (Kaplan, 1969), and strongly positive thyroid cytoplasmic and gastric parietal cell antibodies were detected both in serum and in pericardial fluid. The possibility that a delayed hypersensitivity reaction to an antigen present in pericardial fluid might be responsible for the effusion was examined by assessing the ability of the patient's lymphocytes to transform in response to autologous pericardial fluid assessed morphologically and by the incorporation of $\mathrm{H}_{3}$ thymidine; no specific lymphocyte transformation could be shown.

\section{Comment}

The present case showed many of the features described in the postmyocardial infarction syndrome, but tamponade in this syndrome is rare and when present is attributed to a haemorrhagic pericarditis in patients on anticoagulants (Dressler, 1959; Claurec et al., 1966; Prewitt, 1968). Such treatment was not used in this patient and the pericardial fluid was straw-coloured without blood on microscopy. The time interval of 10 days between the myocardial infarct and the development of the pericarditis is that usually observed in this syndrome, and a rise in the E.S.R., the presence of heart antibodies, and the response to corticosteroid drugs provided confirmatory evidence. No other cause for the pericardial effusion could be shown. There was no clinical or radiological evidence of an effusion three days after the

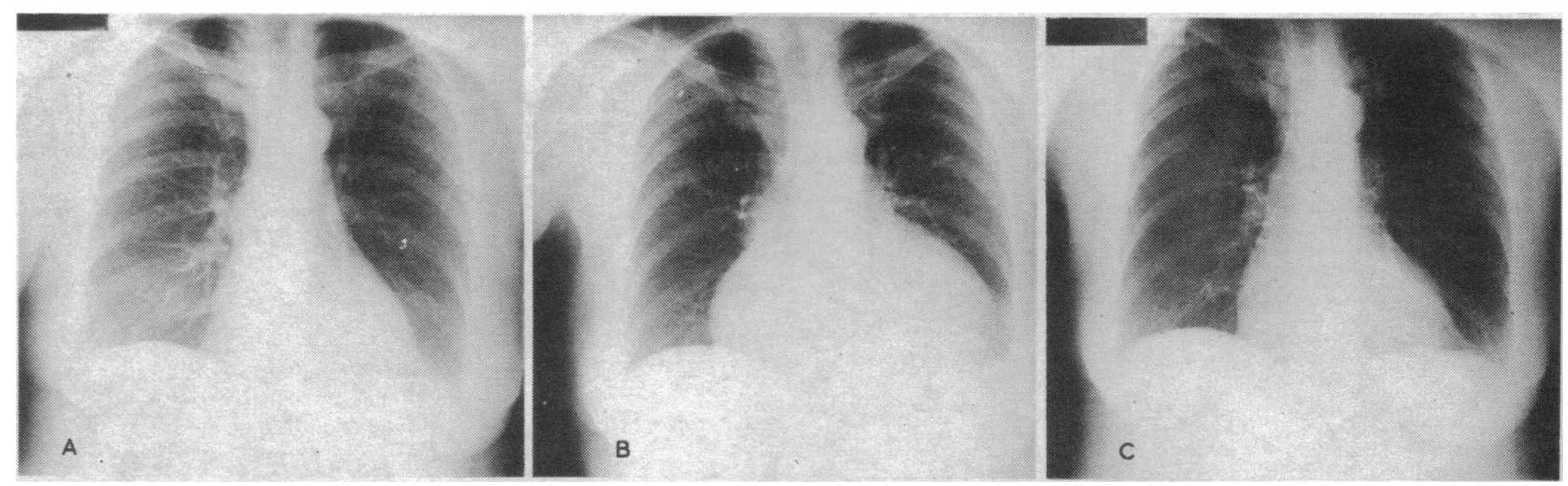

Radiographical appearances of heart during development and treatment of pericardial effusion. A, Three days after myocardial infarction. B, At time of pericardial tamponade. C, After treatment with prednisolone and aspiration. 
infarct, and it resolved completely after aspiration and corticosteroid drugs with a fall to normal of the E.S.R.

A hypersensitivity reaction to autologous heart tissue, possibly altered antigenically by ischaemia, has been postulated as the cause of the postmyocardial infarction syndrome. This case was remarkable because of the severity of the pericardial reaction observed, which we think may have been related to the patient's strong personal history of allergy and her ability to develop auto-antibodies, but immunological studies failed to elucidate the pathogenesis.
We wish to thank Mrs. Christine Ponsford and Mrs. Jennifer Thomas for technical help and Professor P. B. Beeson for permission to report this case of a patient under his care.

\section{References}

Claurec, M., Cristol, R., and Raharissan, S. (1966). Presse Médicale, 74, 965. Dressler, W. (1959). Archives of Internal Medicine, 103, 28. Kaplan, M. H. (1969). Progress in Allergy, 13, 408. Prewitt, J. A. (1968). American Heart fournal, 76, 139.

\section{Pulmonary Complications after Oesophagogastroscopy using Diazepam}

\author{
P. A. TAYLOR, P. B. COTTON, R. M. TOWEY, \\ A. E. GENT
}

British Medical fournal, 1972, 1, 666

Diazepam has so facilitated many diagnostic and therapeutic procedures (British Medical fournal, 1970) that possible dangers may be overlooked. We report the cases of two patients out of a series of 1,000 patients undergoing fiberoptic oesophagogastroscopy in this hospital who subsequently developed pulmonary complications.

\section{Case Reports}

Case 1.-An emaciated 69-year-old man admitted to hospital with pyloric stenosis was treated by gastric suction and intravenous fluids. Pulmonary tuberculosis was diagnosed on $x$-ray examination and subsequent sputum culture and chemotherapy was started. One week later, after overnight starvation, he underwent oesophagogastroscopy with the ACMI 7089A fiberscope. Diazepam $10 \mathrm{mg}$ and atropine $0.6 \mathrm{mg}$ were given intramuscularly one hour beforehand and the pharynx was sprayed with $4 \mathrm{ml}$ of $4 \%$ lignocaine. He became stuporous after a further $5 \mathrm{mg}$ of diazepam given intravenously immediately before the procedure, which was performed in the left lateral position. The examination was terminated when he vomited and became cyanosed. Signs and $x$-ray appearances were consistent with aspiration of vomit. Despite having oxygen therapy overnight he was successfully anaesthetized for laparotomy the next day. Anaesthesia was induced and he was intubated after preoxygenation, cricoid pressure (Sellick, 1961), and suxamethonium chloride. Chest physiotherapy was then performed (Clement and Hubsch, 1968). At laparotomy a gastric carcinoma was found and bypassed and he left hospital three weeks later.

Case 2.-A woman aged 69 was admitted to hospital with pronounced weight loss and lower abdominal pain. Barium-meal

St. Thomas's Hospital, London S.E.1

P. A. TAYLOR, M.B., B.S., F.F.A. R.c.s., Senior Anaesthetic Registrar

P. B. COTTON, M.B., B.CH., M.R.C.P., Senior Medical Registrar

R. M. TOWEY, M.B., CH.B., Anaesthetic Registrar

A. E. GENT, M.D., M.R.C.P., Senior Medical Registrar examination showed a high lesser-curve gastric ulcer, probably neoplastic. This was confirmed by fiberendoscopy (and biopsy) using the same technique as described above except that the intravenous dose of diazepam was $10 \mathrm{mg}$ and the examination was completed without obvious incident. Fever developed, however, and seven days later there was obvious pulmonary consolidation and abscess formation on the chest $x$-ray film, which had previously been clear. There was a good response to physiotherapy and Septrin given by mouth and she survived exploratory laparotomy one month later. It is of interest that she had developed a lung abscess in 1941 after pneumonia.

\section{Comment}

Parenteral diazepam has been used both for induction of anaesthesia (Brown and Dundee, 1968) and as a satisfactory tranquillizer during radiology and such procedures as minor oral surgery and conservative dentistry (Brown et al., 1968), cardioversion, and endoscopy.

Over 1,000 fiberendoscopic examinations have been performed at this hospital using topical pharyngeal anaesthesia and diazepam given slowly intravenously until dysarthria and hemiptosis appear. The occurrence of only two known pulmonary complications speaks for the safety of this drug, which enables most endoscopies to be performed on outpatients.

It is, however, important to remember that diazepam caused suppression of the laryngeal closure reflex in eight out of 19 patients tested by Healy and Vickers (1971). The present two patients were both old and debilitated. The problem at fiberendoscopy is further complicated by the use of topical pharyngeal anaesthesia and the fact that the endoscope may facilitate vomiting or regurgitation of retained gastric contents present despite prolonged starvation (as in Case 1). These considerations demand that tipping trolleys and suction and resuscitation equipment should be available. There is a growing practice of using diazepam sedation in unstarved patients for minor surgical procedures. In some cases full controlled general anaesthesia may prove safer.

\section{References}

British Medical fournal, 1970, 2, 377.

Brown, P. R. H., Main, D. M. G.; and Larson, J. I. M. (1968). British Dental fournal, 125, 498 .

Brown, S. S., and Dundee, J. W. (1968). British fournal of Anaesthesia, 40, 108.

Clement, A. J., and Hubsch, S. K. (1968). Physiotherapy, 54, 355.

Healy, T. E. J., and Vickers, M. D. (1971). Proceedings of the Royal Society of Medicine, 64, 85.

Sellick, B. A. (1961). Lancet, 2, 404. 